\title{
Impact of consumer's values on ethical goods word of mouth behaviors
}

\author{
Nida Rasheed ${ }^{1}$, Fatima Afzal ${ }^{2}$
}

\section{Abstract}

This study is expected to quantify the impact of value image, strategic image, and trajectory image on ethical goods word of mouth behavior based on the recent call for further research (Jayawardhena et al., 2016). We have collected data from 177 consumers from Lahore city, using a mall intercept technique. The response rate remains $48 \%$. Before, testing the hypothesis, we applied reliability analysis, and most of our measures were found to be reliable for further analysis. The results have practical implications for marketers and give more insight into image theory.

Keywords: Value image, Trajectory image, Strategic image, Ethical WOM behavior, Image theory.

There are wide ranges of decision-making strategies that specify that consumers are adaptive decision-makers, who retort and adapt to their environment based on their values, goals to achieve certain outcomes (Beach and Mitchell 1990, Beach 1997, Beach 1998). Much of the limitations of Normative decision theory where the consumer is a rational decision-maker and makes informed decisions based on complete information, naturalistic decision theory (NDT) has evolved to predict the and describe the actual decision behavior. Among different models, 'image theory' is expansively and thoroughly developed NDT (Klein et al., 1993). According to image theory, decision-makers have limited cognitive capacity and make decisions within a decision frame (Beach, 1993). Decision-makers store that part of the knowledge which is considered relevant to the current decision, and this knowledge structure comprises three images; strategic image, value image, and trajectory image (Beach, 1998).

In this study, there is specifically an agreement on account of ethical consumption. It has been acknowledged that there is an impact of ethical consumption on the business environment at large and particularly in marketing. Moreover, investigation on how ethical buying decisions making of consumers evolve in each milieu has yet to be unraveled. There are four major gaps discussed in this context, which are consumer choices reflecting through their self-interests. Consumer to consumer interplay, through word of mouth about the goods by expressing an attitude or belief towards the ethical consumption of products. However, this is, in the long run, does not follow, and at last, gender roles affect decision making.

Due to environmental concerns, consumers are interested in environmentally friendly products and healthier organic products free from genetically modified organisms (GMOs) and the products reaching them as a result of fair-trade policies. Consumers will most likely behave environment-friendly when they have developed a positive attitude that concerns the environment. They also support environmentally friendly products like non-GM foods to others. In simple words, when people are environmentally concerned, they will go for environment-friendly products to align this behavior with their ethical attitude. Then they will strongly recommend this activity to others to follow; here comes the part of word of mouth (Jaywardhena, 2017).

\section{Problem Statement}

No specific structural process prevails to explore the ethical consumption of patrons in the marketplace. So, here we explore the ethical consumption of buyers in the markets engrossed in making decisions about purchasing certain products like organic, non-GM (genetically modified), and FT (fair trade) brands. There is a challenge of consumer ethical decisions that they are affected by their self-interests, as such decisions include incurring the cost of consumers. However, premium prices are not always included in all ethical purchases, as there are also transaction costs. It shows the convenience disruption of shopping in markets.

\section{Research Question}

- What is the effect of consumer's values on word of mouth behavior?

\section{Objectives}

- This study expands our understanding of image theory by examining all 3 images (values, goals, and strategies) simultaneously in the same decision context

- To examine Word of Mouth behaviors in influencing ethical consumer decisions.

\section{Significance}

In marketing, decision making on ethical grounds is wellestablished regard. In this study, we will further revise the degree that moral is a description frame to gauge the decision-making process. But for now, we will consider the aspects of pro-social and pro-environment in an established view that it has in the marketing literature. In two influential pieces of research, this literature has been tied up, and explain that users with ethical behaviors are social-conscious as well as ecological anxious. Furthermore, with the increasing literature exploring the ethics of consumers as a category, very less has been investigated of specific ethical consumer decision making processes.

${ }^{12}$ UCP Business School, University of Central Punjab, Pakistan. Corresponding author: nidarasheed44@ gmail.com 


\section{Research Gap}

- Despite a growing literature that explores ethical consumers as a category, less is known about ethical decision processes among consumers (Lye and Fausnaugh, 2005)

- No relevant study exist that that examine ethical consumption in supermarkets of Pakistan in the Image theory perspective.

\section{Literature Review}

\section{Ethical Goods WOM Behavior}

WOM is considered the most important information source in consumers' buying decisions (Litvin, 2008) and intended behavior. Schiffman and Kanuk (2000), in their study, suggested that WOM recommendation is an influential tool in consumer's informational search, evaluation criteria, and subsequent decision making. We have developed this hypothesis statement that those consumers who possess strong ethical values and principles will engage more in WOM activities to influence others and behave in a way they do. Thus, an individual who is a strong believer in organic, non-GM, and FT products is more likely to become a volunteer advocate of the products they 'evangelize' than others having indifferent attitudes.

Table 1: Constructs and Definitions

\begin{tabular}{ll}
\hline Constructs & Definitions \\
\hline Value Image & $\begin{array}{l}\text { Value image constituents are the decision maker's } \\
\text { imperatives for his or her as well as criteria for the } \\
\text { rightness or wrongness of any particular decision about a } \\
\text { goal or plan for attaining that goal(Beach, 1998). } \\
\text { The 'strategic image' includes the different plans, tactics } \\
\text { and forecast activities that decision makers may use. In a } \\
\text { decision chain, plans typically begin with goal adoption } \\
\text { and end with goal achievement (Beach, 1998). } \\
\text { The trajectory image consists of one's agenda for the } \\
\text { future, the 'strategic' blueprint for where one is going, } \\
\text { the ends one elects topursue in light of one's self image, } \\
\text { the landmarks one foresees along one's idealized life } \\
\text { course (Beach, 1998). } \\
\text { WOM is a person-to-person communication tool, between } \\
\text { a communicator and a receiver, who perceives the } \\
\text { information received about a brand, product, or service as } \\
\text { non-commercial. (Arndt, 1967) }\end{array}$ \\
\hline
\end{tabular}

Value Image

Values determine the 'attributes' the consumers want in a product while making purchase decisions (Bray et al., 2010). Morrell and Jayawardhena (2010) provided support to the idea that consumers' values are interrelated to ethical purchase behavior considering organic, FT goods, and Non-GMO products.

H1: There is a positive relationship between value image and ethical goods Word of Mouth behavior. (Ethical goods is a collective term used for organic, FT and non-GM goods)

\section{Strategic Image}

Jayawardhena in 2017 explains that different plans, predictions, and stratagems are included in the strategic image to make decisions by users. During any decision process, the first step of planning is usually goal adoption, which ends towards goal achievement at last. Stratagems are some plan of actions, whereas; predictions are any forecasts of future happenings, but the condition is for plans and stratagems to be followed. Shoppers with ethical values may make ethical choices about consumption because this attribute has become the firmer part of their personalities.
Considering the above hypotheses, if consumers feel ethical consumption a strong belief, then they will surely recommend their ethical behavior to others through word of mouth to adopt. Evangelizing is also used to explain this relation that buyers strongly believe in organic, non-GM, and FT products. They can be redeemed in contrast to those having indifferent attitudes, in short, to give away fairness for manufacturers. Environmental and also social activism is aligned with such understandings here.

H2: There is a positive relationship between strategic image and ethical good Word of Mouth behavior.

\section{Trajectory Image}

It is also discussed by Jayawardhena in 2017 in the light of empirical studies that those agitated towards the environment are most likely to behave in ethical, friendly behavior. The trajectory image also influences ethical behaviors. The main predictors for pro-environment behaviors are those of pro-environmental concerns of consumers. Similarly, households with these concerns will also behave ethically in-home composting. Birgelen in 2009 states that users who are more agitated towards environmental are most likely to go for the purchase of ecologically friendly drinks (having careful packaging).

H3: There is a positive relationship between trajectory image and ethical goods Word of Mouth Behavior.

\section{Theoretical Framework}

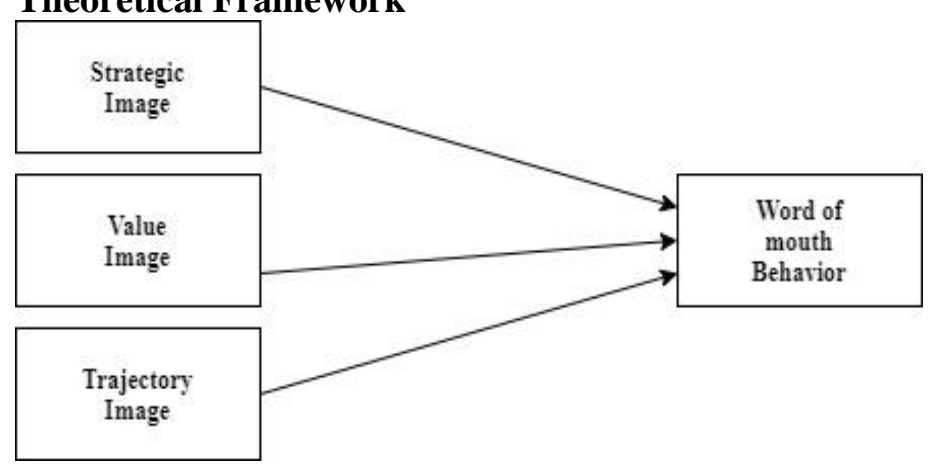

Figure 1: Theoretical Framework Methodology

There are three independent variables and two dependent variables. Independent variables comprise value image, strategic image, trajectory image, and dependent variables that constitute ethical goods WOM behavior. The measurement scale was adopted from Jayawardhena (2016).

\section{Instrument}

To measure each image (trajectory, strategic, and value), we included six items coded a 5 point (strongly disagree to strongly agree) Likert response scale. Each scale was designed to contain three global and three specific measures. The global measures were designed to tap beliefs about broad social scope while specific measures targeted individual decision-makers. For each of FT, non-GM and organic products, we asked two WOM behavioral questions like 'if asked I would say good things about non-GM/ FT/organic food' also 'I would recommend nonGM/FT/organic food to family and friends.

\section{Sample and Data Collection}

We sampled consumers from large metropolitan Lahore city, using a mall intercept technique. We collected data from 177 
respondents using convenience sampling. The data was collected while the consumers were inside the shopping mall, mostly grocery area. We conducted a short survey over one week during normal shopping hours, approaching every ninth person screening them and requesting them for their participation. There was no evidence of response error or systematic variation between data was found. We did not offer any incentive to the respondents.

\section{Results}

Data were analyzed using multiple regression analysis. It is a statistical technique used to analyze the proposed hypothesis statements. The tables given below, shows the correlation of the variables and the results if multiple regression analysis. Refer to Table 4, none of the variables were removed. R square is .805 As $\mathrm{P}<.05$ in strategic image and WOM; there exists a significant relationship between the two variables. Therefore, hypothesis 1 is accepted. Similarly, $\mathrm{P}<.05$ in trajectory image and WOM, a significant relationship among the two variables. However, in value image and WOM $\mathrm{P}=.140$, and it is not less than .05 ; therefore, the relationship between the two variables is insignificant. Thus, hypothesis 1 is rejected.

\section{Reliability Analysis}

Table 2: Reliability Analysis

\begin{tabular}{lccc}
\hline Construct Name & $\begin{array}{c}\text { Cronbach } \\
\text { Alpha }\end{array}$ & $\begin{array}{c}\text { Number of } \\
\text { Original Items }\end{array}$ & $\begin{array}{c}\text { Deleted } \\
\text { Items }\end{array}$ \\
\hline Word of Mouth Recommendation & 0.89 & 2 & 0 \\
Value Image (VI) & 0.777 & 3 & 0 \\
Strategic Image (SI) & 0.712 & 2 & 0 \\
Trajectory Image (TI) & 0.897 & 2 & 0 \\
\hline
\end{tabular}

Refer to Table 2; the variable (WOM recommendation) consists of 5 items. The Cronbach Alpha value for the variable is 0.817 , which is well above the threshold level of 0.7 . The variable (Value Image) consists of 5 items. The Cronbach Alpha value for the variable is 0.777 , which is well above the threshold level that is 0.7. The variable (Strategic Image) consists of 5 items. The Cronbach Alpha value for the variable is 0.712 , which is well above the threshold level that is 0.7 . The variable (Trajectory Image) consists of 5 items. The Cronbach Alpha value for the variable is 0.897 , which is well above the threshold level that is 0.7. It shows that there exists internal consistency among the variables. Age and gender have been kept as controls.

Table 2: Descriptive Statistics

\begin{tabular}{lccccc}
\hline Variables & S.D & Mean & Median & Mode & SE of Mean \\
\hline Gender & 1.179 & 3.327 & 4 & 4 & 1.17 \\
Age & 1.134 & 3.395 & 4 & 4 & 1.133 \\
Value Image & 0.544 & 3.709 & 3.666 & 3 & 0.544 \\
Strategic Image & 0.786 & 3.463 & 3.500 & 4 & 0.786 \\
Trajectory Image & 0.7342 & 3.731 & 3.666 & 4 & 0.734 \\
WOM behavior & 0.364 & 4.057 & 4.166 & 4 & 0.364 \\
\hline
\end{tabular}

\section{Correlation Analysis}

Table 3 shows the values for correlation between the study variables. The correlation matrix indicates that there is a positive and significant relationship between value image and WOM at .564 , strategic image and value image at .569 , trajectory image and strategic image at .758 respectively.

Table 3: Correlation Matrix

\begin{tabular}{lcccc}
\hline Latent variables & WOM & VI & SI & TI \\
\hline WOM & 1 & & & \\
VI & $.564^{* *}$ & 1 & & \\
SI & $.853^{* *}$ & $.569^{* *}$ & 1 & \\
TI & $.824^{* *}$ & $.524^{* *}$ & $.758^{* *}$ & 1 \\
\hline
\end{tabular}

H1: There is a positive relationship between value image and WOM behavior.

The first hypothesis there exists a positive relationship between value image and WOM behavior is rejected $(\mathrm{r}=.564 ; \mathrm{p}=.140)$ where $\mathrm{N}=177$

Null H1= H10: there is no relationship between value image and WOM behavior. The null hypothesis is accepted $(r=.564$; NS).

H2: There is a positive relationship between strategic image and WOM behaviors.

This hypothesis is accepted $(\mathrm{r}=.853 ; \mathrm{p}<0.05)$. Hence, we can conclude between that there exists a positive relationship between strategic image and WOM behaviors where $\mathrm{N}=177$

H3: There is a positive relationship between trajectory image and WOM behaviors

This hypothesis is accepted $(\mathrm{r}=.824 ; \mathrm{p}<0.05)$. Hence, we conclude that exists a positive relationship between trajectory image and WOM behaviors where $\mathrm{N}=177$

\section{Regression Analysis}

Three hypotheses have been analyzed using regression analysis. The results are summarized in table 4. Results show that Strategic image has a positive impact on $\operatorname{WOM}(\beta=.513, \mathrm{p}=.000, \mathrm{t}=9.465)$ at .001 level of significance. However, value image does not have a positive impact on $\operatorname{WOM}(\beta=.061, \mathrm{p}=.140, \mathrm{t}=1.481)$, so based on statistical value hypothesis 1 is not accepted. Conversely, trajectory image has a positive impact on WOM $(\beta=.404, p=.000$, $\mathrm{t}=7.719$ ), therefore, hypothesis 3 is supported. In addition to it, control variables age, gender remained non-significant in regression models.

Table 4: Regression Analysis

\begin{tabular}{llllll}
\hline Variable Name & Beta & Std. Error & t-value & P-value & Decision \\
\hline 1.SI WOM & 0.513 & 0.025 & 9.465 & 0 & Supported \\
2.VI WOM & 0.061 & 0.028 & 1.481 & 0.14 & Not supported \\
3.TI WOM & 0.404 & 0.026 & 7.719 & 0 & Supported \\
Model & & & & & \\
Specification & & & & & \\
$\mathrm{R}^{2}$ & & & & & \\
Adjusted $\mathrm{R}^{2}$ & & & & & \\
\hline
\end{tabular}

\section{Discussion}

The first contribution is value-driven decisions by consumers to augment the choice assimilation by reconnoiter specific mechanisms and other major factors contributing to the decision process. Thee appropriate know-how of value-driven purchase choices. A real-world milieu of the market is developed to study measures into consideration. It is a view that image theory is a realistic approach to identifying choices and opting for the best one (Beach 1998). Comprehensively, the outcome shows that ethical behavioral decisions can be described by image theory. Similarly, we manifest that there is an impact of value, strategic, and trajectory image on behavior. It is also assessed that the value image has a greater effect than the two others.

They also contribute to comprehending purchasing and psychological behaviors instead of pricing and branding aspects, from where many other latent results were generated. A rise in unethical practices is one outcome that using the strategy to increase sales of those goods manufactured or sourced unethically. Maybe it is because of those firms that use essential features, not 
harmful products, instead of focusing on the major issue, which is inequity. Furthermore, the availability of improved and increased understanding of behavioral decision-making context inspires us to readdress these propositions further in social sciences, to study the impact of uncommercial aspects like spiritual beliefs, morals, and values.

\section{Conclusion}

Just like others, we also reason here that non-GM, organic, and FT products purchase decision is not unethical. They might be certifying as pro-social or environmental. Findings suggest that the ethical process is misunderstood as the self-interest factor is not the reason behind any decision-making motivation. Yet, some purchasing decisions can be because of selfish reasons for products like non-GM or organic products if the perspective of the user is that they are healthier. When we talk about taste preferences, it is also assumed that FT brands' decisions reason is pure selfishness. According to our observations, there is a continuous alliance between the ratings of specific value images and buying decisions, giving assurance of them descriptions as ethical. But, there one description regarding non-GM and organic products is that they might be motivated by one's selfish reasons. We assumed our study as ethics based on the view of literature from where this study has been anchored. But after our assessments and further evaluations and anonymous observer's viewpoints, we have come to this point that considering it as a value-driven rather than ethical is more appropriate.

According to anonymous observers' view, the reason for doing so is that it is more likely a value-laden, or a normative term for behavior instead of analytical illustration. We propose prior that some decisions can be selfish, unethical, personal, and selfinterested. For non-GM, organic, and FT brands are not confirmed as ethical buying or beneficial. FT label ones did not specifically guarantee better state of affairs all through the supply chain as selecting any product must be based on deep and accurate knowledge of that product, its company, and the region in which it has been manufactured. Sustainable development is not assured by FT label products as well. FT from ethical trade is distinguished by Smith and Barrientos (2005) carefully. The debate regarding the risk factor presence in GM crops is highly complex as it drives scientific researchers towards risk assessment. Many environmental benefits are related to GM crops like less carbon, fewer water footprints, high productivity, and low need for biocides. Thus, refusing them can automatically consider as unethical. The yield of organic food per hectare is less, meaning it needs more agricultural space. This means that they must be expensive for societies to devour them. We can say that there is a complex interplay between organic and GM mix. We acknowledge the anonymous reviewer's comments, that we have come to know about the value-driven choices between organic, GM, and FT. This description is considered an improvement in literature and can be for future researches in marketing regarding ethical decision making.

While presenting the notion of values in the decision-making process, it is crucial to note that image theory is not a description of bounded rationality. It is a description of the non-rationality of decisions. In simple words, rules, habits, and values are all involved in decision making. Image theory explains that the first step in making any decision is screening the options of whether to do something or not and how (Beach and Strom 1989). These options were further evaluated as non-rationally. Alternatively, option analyzed with a view that it fits values or real-life goals. If they are well-matched, we say that they are also approved. Rarely, a very small ratio of options survived the fits and screening process. Preconscious behaviors are very well explained with the help of image theory. Importantly, when we talk about the food shopping context function of values in ethical decision making can be better understood.

This study also covers the debate regarding the age and sex in the decision-making process. Many researchers in their studies argue that gender plays an important role. They suggest that males are not that much ethical oriented as females are. However, this is not a compatible result, as Doran in 2009 explains that there is no difference in an ethical decision based on gender. Decisions can be affected by age, as said by Moores and Chang in 2006. They suggest that older people occupy strong ethics and values and are many realistic or idealistic consumers as compared to young ones. But some say that this behavior might be because younger buyers are not that many rich as compared to older consumers, and we all know the notion that ethical goods are primarily expensive than other goods. So, younger customers are most likely to support organic or ethical products and less likely to purchase them. It will surely be evaluated through future researches on whether younger and older consumers' behavior differs because of the price factor. One more complication is that the notion about ethical goods like organic, non-GM, and FT is a newly found innovation. Thus, older users might not be very aware of them as younger and middle-aged people are, which again a non-linear result.

\section{Future Research \& Limitation}

Notwithstanding theoretical and practical contributions, we acknowledge limitations, for instance, potential common method variance. This could have been a greater threat if respondents were aware of the conceptual framework of interest. However, respondents were not informed of the purpose of the study, and all items were separated and mixed, making it difficult for respondents to detect which items measured which factors. The cross-sectional nature of the study, along with the use of survey data, allows for an understanding of directional relationships amongst the constructs but does not allow causal inferences. However, the current findings do shed new light on our understanding of the values of ethical consumption behaviors. This study did not identify where the products were purchased. This may be important because there may be a relationship between the specific retail outlet and purchasing decisions in that store. Just as some shoppers shop around for bargains, could it be that some shoppers shop for FT goods stores based upon corporate reputation, and could influence managerial outcomes vis-à-vis store policy. Despite all these notions, variables like age, gender were kept as a control. However, their impact on the ethical behaviors of consumers to make decisions need to be investigated further.

Equally, we have not been able to explore the distinction between gender and sex fully with this design. Future research using 
controlled experiments, or a longitudinal design could enhance our understanding of certain relationships. As suggested earlier, we propose that future research examine whether the curvilinear effect on purchasing we found is due to both younger consumers and older consumers being more price conscious. The current study was undertaken in Lahore, and therefore, another area that would benefit further investigation is the effect of national contexts on ethical consumption behaviors.

\section{Implications for Manager and Firms}

These research findings could be beneficial for those firms who want to launch ethical product lines or have them. It also contributes to the idea that shoppers might use scripts, frames, and sign postings to navigate the markets' twists. Those providing ethical products can underline their attributes to guide consumers in decision making. Marketers also need to think of more effective ways in which they can offer ethical products to consumers. They need to put considerable values into marketing mix strategies rather than focusing on brands and their premium purchase prices. Marketers must use different methods to understand the strategy of micro-merchandising, like observations. We are familiar with the idea of scripted and conscious purchasing in our everyday life by illustrating consumer with ethical awareness, a phrase most used. Perhaps it is just a fancy phrase, but a theoretical and methodological dare leads to the idea of purchasing ethics among consumers as it is not present in scripted behaviors.

\section{References}

Beach, L. R. (1990) Image theory: decision making in personal and organizational contexts, John Wiley \& Sons, West Sussex.

Beach, L. R. (1993) Image theory: personal and organizational decisions, In Decision making in action: models and methods (Eds, Klein, G. A., Orasanu, J., Calderwood, R. and Zsambok, C. E.) Ablex Publishing Corporation, Norwood, N.J., pp. 148157.

Beach, L. R. (1997) The psychology of decision making: people in organizations, Sage Publications, Thousand Oaks, Calif.

Beach, L. R. (Ed.) (1998) Image theory: theoretical and empirical foundations, L. Erlbaum Associates, Mahwah, N.J.

Beach, L. R. and Mitchell, T. R. (1978) A contingency model for the selection of decision strategies, Academy of Management Review, 3, 439-449. Beach, L. R. and Mitchell, T. R. (1987) Image theory: Principles, goals, and plans in decision making, Acta Psychologica, 66, 201-220.

Beach, L. R. and Mitchell, T. R. (1990) Image theory: a behavioral theory of decision making in organizations, In Research in organizational behavior, Vol. 12 (Eds, Staw, B. M. and Cummings, L. L.) Jai Press Inc., Greenwich, Connecticut, pp. 141.

Bray, J., Nick, J., \& Kilburn, D. (2010). An exploratory study into the factors impeding ethical consumption. Journal of Business Ethics, 98(4), 597-608. doi:10.1007/s10551-010-0640-9

Klein, G. A., Orasanu, J., Calderwood, R. and Zsambok, C. E. (Eds.) (1993) Decision making in action: models and methods, Ablex Publishing Corporation, Norwood, N.J

Morrell, K., \& Jayawardhena, C. (2010). Fair trade, ethical decision making and the narrative of gender difference. Business
The starting point might be the decision frame. Similarly, in the market, one considers it a place of convenience for acquiring products. The other believes it as a place where whatever the decision they make could have ethical outcomes. These considerations might be affected by the morals and values of consumers. Here we propose that it is crucial to acknowledge supermarket characteristics, but another factor must be aligned: moral values, as implied in image theory. This work can also enhance the ethical market conditions if consumers believe that their behavior can cut the injustice prevailing in marketplaces (FTgoods). In simple words, marketers should convey this message that consumers' behaviors impact general issues. Many ethical goods conveyed this message already that how they will affect the market and adds to the idea that consuming those items could help someone at the other end and the supply chain. It is also concluded from the effects that the findings of the trajectory and value images are helpful for social marketers as they suggest others to develop pro-social behaviors. If social marketers can request people desires for prevailing fairness in the world, most of the chances are that consumers might act accordingly. Specifically, we suggest that on the appeals of marketers, they make consumers believe that there are injustice and need for change. Consumers can act ethically and make the right choices with the right behaviors.

Ethics: A European Review, 19(4), 393-407. doi:10.1111/j.14678608.2010.01598.x

Robbins, S. P (2003). Management 7th ed. N.J.: Prentice-Hall

Schiffman, L. G., \& Kanuk, L. L. (2000). Consumer behavior. Englewood Cliffs, NJ: Prentice Hall. 